\title{
Monitoring and analysis of rice pathogen Ustilaginoidea virens isolates with resistance to sterol demethylation inhibitors in China
}

\author{
Xiayan Pan, Huijuan Cao, Junjie Yu, Mina Yu, Zhongqiang Qi, Tianqiao Song, Yan Du, Mingli Yong, \\ Rongsheng Zhang, Xiaole Yin and Yongfeng Liu*
}

\begin{abstract}
Rice false smut (RFS), caused by Ustilaginoidea virens (Cooke) Takah, is an important fungal disease of rice. In China, sterol demethylation inhibitors (DMIs) are common fungicides used to control RFS. In a previous study, we detected two propiconazole-resistant U. virens isolates in 2015 in Huai'an city, Jiangsu Province, China. In the current study, we detected six propiconazole-resistant isolates out of $180 \mathrm{U}$. virens isolates collected from rice fields in Jiangsu Province in 2017, and found they were from three different places (Xuzhou, Huai'an and Jintan). All these six propiconazole-resistant isolates were cross-resistant to three other sterol demethylation inhibitor (DMI) fungicides, i.e. difenoconazole, tebuconazole, and epoxiconazole. Among them, two isolates (2017-61 and 2017-170) had high fitness. Through sequencing and RT-qPCR analysis, we found that the expression levels of CYP51 and its encoded protein were significantly increased in the propiconazole-resistant isolates with a "CC" insertion mutation upstream of the CYP51 coding region compared to the propiconazole-sensitive isolates. In addition, propiconazole stimulated CYP51 expression in all isolates. Propiconazole also stimulated the accumulation of CYP51 protein in propiconazole-sensitive isolates and propiconazole-resistant isolates without mutation, but not in propiconazole-resistant isolates with the "CC" mutation. According to JASPAR database analysis, the predicated functional binding sites for propiconazole-resistant isolates with a "CC" insertion mutation and propiconazole-sensitive isolates were different. Given the high fitness of the propiconazoleresistant isolates, the development of resistance to DMIs in U. virens should be monitored. Furthermore, we speculated that the over-expression of CYP51 may contribute to DMl resistance in U. virens with the "CC" insertion mutation.
\end{abstract}

Keywords: Ustilaginoidea virens, Propiconazole, Resistance monitoring, Fitness

\section{Background}

Rice false smut (RFS), caused by Ustilaginoidea virens (Cooke) Takah, is a major fungal disease in most ricegrowing areas all over the world. The typical symptom of this disease is the formation of false smut balls in rice grains, which affects the overall quality of rice (Zhou et al. 2008). $U$. virens also produces toxic secondary metabolites, including ustilaginoidins and ustiloxins, which threaten food and feed safety (Qiu et al. 2019). Currently, the application of fungicides is a fast and

\footnotetext{
* Correspondence: liuyf@jaas.ac.cn

Institute of Plant Protection, Jiangsu Academy of Agricultural Science, Nanjing 210014, China
}

\section{BMC}

(c) The Author(s). 2020 Open Access This article is licensed under a Creative Commons Attribution 4.0 International License, which permits use, sharing, adaptation, distribution and reproduction in any medium or format, as long as you give

appropriate credit to the original author(s) and the source, provide a link to the Creative Commons licence, and indicate if changes were made. The images or other third party material in this article are included in the article's Creative Commons licence, unless indicated otherwise in a credit line to the material. If material is not included in the article's Creative Commons licence and your intended use is not permitted by statutory regulation or exceeds the permitted use, you will need to obtain permission directly from the copyright holder. To view a copy of this licence, visit http://creativecommons.org/licenses/by/4.0/ tion inhibitors (DMIs), mainly including propiconazole, difenoconazole and tebuconazole, have been most widely used to control RFS in China (Chen et al. 2013). However, due to the intensive application of DMI fungicides, resistance has been detected in several important pathogens, such as Monilinia fructicola, Puccinia triticina, Penicillium digitatum, and Erysiphe graminis, in recent years (Schepers 1985; Delye et al. 1998; Luo and Schnabel 2008; Price et al. 2015). In 2015, Zhou et al. (2019) reported propiconazole-resistant isolates of $U$. virens and found one with high fitness. Therefore, monitoring propiconazole resistance in the field and evaluating its resistance risk 
are particularly important for the management of DMI resistance in RFS.

DMIs are broad-spectrum fungicides that inhibit ergosterol biosynthesis by targeting sterol $14 \alpha$-demethylase CYP51, a key enzyme in sterol biosynthesis. Homologous genes of CYP51 have been found in phytopathogenic fungi Fusarium graminearum, Magnaporthe oryzae, and Aspergillus spp. (Mellado et al. 2001; Yin et al. 2009; Yan et al. 2011). However, only one CYP51 was identified in the $U$. virens genome (Wang et al. 2015). The common mechanisms of fungal resistance to DMI include mutations in the target CYP51 gene; overexpression of the CYP51 gene, and enhanced efflux pumps that are encoded by ATPbinding cassette (ABC) transporter ( $\mathrm{Ma}$ et al. 2006; Kretschmer et al. 2009; Cools et al. 2010, 2012; Wang et al. 2015; Tsao et al. 2016). In F. graminearum, resistance to DMIs was not only related to the mutations of CYP51A, but also related to the ABC transporter (Ammar et al. 2013; Duan et al. 2018). In M. fructicola, a transposable element 'Mona' was inserted in the $113 \mathrm{bp}$ upstream of MfCYP51, which determined the resistance to DMI fungicides (Luo et al. 2008; Chen et al. 2017). In $U$. virens, up-regulation of CYP51 and increased ergosterol biosynthesis were reported to be associated with propiconazole resistance (Zhou et al. 2019). However, due to the lack of resistant field isolates, the resistance mechanism of $U$. virens to DMI fungicides requires further investigation.

Thus, the major objectives of the study are to (i) monitor the resistance of $U$. virens to propiconazole in Jiangsu Province of China, (ii) assess the resistance risk of $U$. virens to DMI fungicides, and (iii) investigate the possible mechanisms of DMI fungicide resistance in $U$. virens.

\section{Results}

Frequency and distribution of propiconazole-resistant isolates of $U$. virens at the sampling regions

A total of 180 field isolates of $U$. virens were used to monitor the resistance of this pathogen to propiconazole, and six of them (2017-2, 2017-6, 2017-61, 2017-170, 2017176 , and 2017-179) could grow on PSA plates containing $1 \mu \mathrm{g} / \mathrm{mL}$ of propiconazole. As shown in Table 1, among these six propiconazole-resistant isolates, two (2017-2 and 2017-6) were isolated from Xuzhou; one (2017-61) was from Huai'an; and three (2017-170, 2017-176 and 2017-179) were from Jintan. The resistance frequency of $U$. virens to propiconazole in these places was $6.7,3.0$, and $10.3 \%$, respectively.

\section{Sensitivity test of the preliminarily screened resistant isolates of $U$. virens to propiconazole}

As shown in Fig. 1, the propiconazole-sensitive isolates 2017-11 and 2017-48 could not grow on PSA plates containing $0.4 \mu \mathrm{g} / \mathrm{mL}$ of propiconazole. However, the six aforementioned propiconazole-resistant isolates could grow on PSA plates with $10 \mu \mathrm{g} / \mathrm{mL}$ of propiconazole. The propiconazole sensitivity $\left(\mathrm{EC}_{90}\right)$ of these resistant isolates significantly increased compared to that of the sensitive isolate 2017-11. All these resistant isolates were lowly resistant to propiconazole with resistance factor (RF) values less than 10.0 (Table 2).

\section{Cross-resistance analysis of propiconazole-resistant $U$. virens isolates to other DMls}

Based on the $\mathrm{EC}_{50}$ values, the isolates $2017-11$ and 2017-48 that were sensitive to propiconazole were also sensitive to epoxiconazole, difenoconazole, and tebuconazole (Table 3). In contrast, all six propiconazoleresistant isolates were resistant to these three tested DMIs with resistance factors (RF) ranging from 2.2 to 4.6, 2.0 to 6.0 , and 1.7 to 3.7 , respectively. It was worth noting that the RF values of 2017-6 to difenoconazole and tebuconazole, and 2017-170 to tebuconazole were less than 1, but the $\mathrm{EC}_{90}$ values of them were much higher than that of the sensitive isolates (Table 3).

\section{Mycelial growth, sporulation and pathogenicity of propiconazole-resistant $U$. virens isolates}

The mycelial growth of all six propiconazole-resistant isolates was slower than that of the propiconazolesensitive isolate 2017-11. However, there was no significant difference in mycelial growth between resistant isolates and the sensitive isolate 2017-48, and the mycelial

Table 1 Frequency and distribution of resistance of Ustilaginoidea virens to propiconazole in 2017

\begin{tabular}{|c|c|c|c|c|}
\hline \multicolumn{2}{|c|}{ Sampling place } & \multirow{2}{*}{$\begin{array}{l}\text { Number of isolates tested } \\
30\end{array}$} & \multirow{2}{*}{$\begin{array}{l}\text { Number of resistant isolates } \\
2(2017-2,2017-6)\end{array}$} & \multirow{2}{*}{$\begin{array}{l}\text { Frequency of resistance (\%) } \\
6.7\end{array}$} \\
\hline Jiangsu & Xuzhou & & & \\
\hline & Huai'an & 33 & $1(2017-61)$ & 3.0 \\
\hline & Jintan & 29 & $3(2017-170,2017-176,2017-179)$ & 10.3 \\
\hline & Nantong & 12 & 0 & 0 \\
\hline & Yangzhou & 30 & 0 & 0 \\
\hline & Nanjing & 22 & 0 & 0 \\
\hline & Ganyu & 16 & 0 & 0 \\
\hline & Yancheng & 7 & 0 & 0 \\
\hline
\end{tabular}




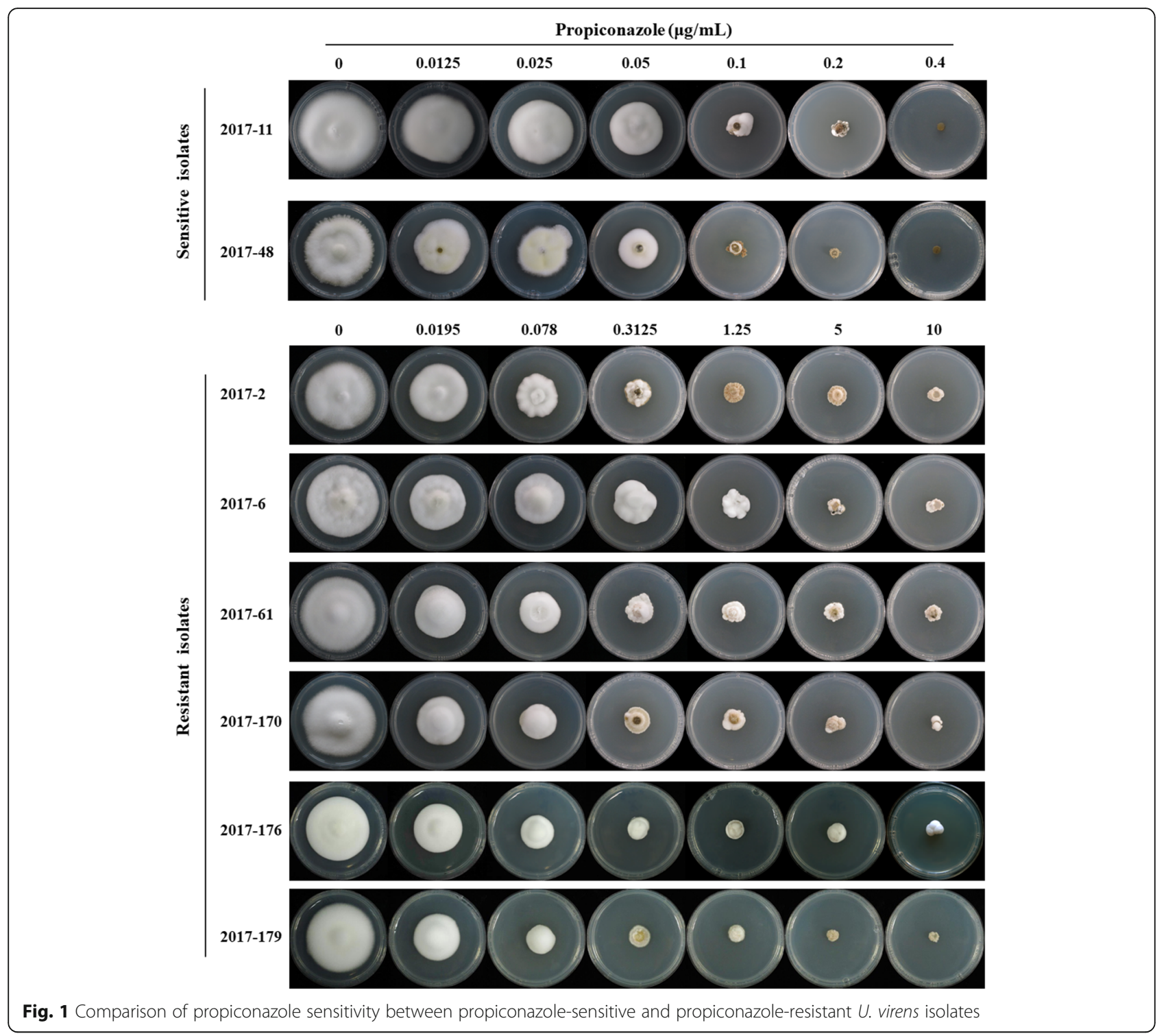

Table 2 Sensitivity of the preliminarily screened resistant isolates of Ustilaginoidea virens to propiconazole

\begin{tabular}{|c|c|c|c|c|c|}
\hline Isolates & Origin & $\mathrm{EC}_{50}(\mu \mathrm{g} / \mathrm{mL})$ & $\mathrm{EC}_{90}(\mu \mathrm{g} / \mathrm{mL})$ & RF & Resistance leve \\
\hline $2017-11$ & Sensitive & 0.053 & 0.26 & I & \\
\hline $2017-48$ & Sensitive & 0.034 & 0.19 & / & \\
\hline $2017-2$ & Resistant & 0.13 & 10.70 & 2.6 & LM \\
\hline $2017-6$ & Resistant & 0.24 & 21.03 & 4.8 & LM \\
\hline $2017-61$ & Resistant & 0.081 & 22.03 & 1.6 & LM \\
\hline $2017-170$ & Resistant & 0.058 & 12.09 & 1.2 & LM \\
\hline 2017-176 & Resistant & 0.12 & 12.80 & 2.4 & LM \\
\hline 2017-179 & Resistant & 0.048 & 3.18 & 1.0 & / \\
\hline
\end{tabular}


Table 3 Cross-resistance of propiconazole-resistant isolates of Ustilaginoidea virens to other DMIs

\begin{tabular}{|c|c|c|c|c|c|c|c|c|c|c|c|c|}
\hline \multirow[t]{2}{*}{ Isolates } & \multicolumn{4}{|l|}{ Epoxiconazole } & \multicolumn{4}{|c|}{ Difenoconazole } & \multicolumn{4}{|l|}{ Tebuconazole } \\
\hline & $\overline{E C_{50}(\mu \mathrm{g} / \mathrm{mL})}$ & $\mathrm{EC}_{90}(\mu \mathrm{g} / \mathrm{mL})$ & $\mathrm{RF}$ & $\begin{array}{l}\text { Resistance } \\
\text { level }\end{array}$ & $\overline{E C_{50}(\mu \mathrm{g} / \mathrm{mL})}$ & $\mathrm{EC}_{90}(\mu \mathrm{g} / \mathrm{mL})$ & $\mathrm{RF}$ & $\begin{array}{l}\text { Resistance } \\
\text { level }\end{array}$ & $\overline{E C_{50}(\mu \mathrm{g} / \mathrm{mL})}$ & $\mathrm{EC}_{90}(\mu \mathrm{g} / \mathrm{mL})$ & $\mathrm{RF}$ & $\begin{array}{l}\text { Resistance } \\
\text { level }\end{array}$ \\
\hline $2017-11$ & 0.037 & 0.18 & 1 & & 0.066 & 0.33 & 1 & & 0.11 & 0.47 & 1 & \\
\hline $2017-48$ & 0.039 & 0.14 & / & & 0.11 & 0.70 & / & & 0.068 & 0.25 & / & \\
\hline $2017-2$ & 0.17 & 3.68 & 4.6 & $L R$ & 0.38 & 11.56 & 4.3 & $L R$ & 0.33 & 8.23 & 3.7 & $L R$ \\
\hline $2017-6$ & 0.099 & 1.86 & 2.7 & $L R$ & 0.048 & 51.76 & 0.5 & / & 0.048 & 11.70 & 0.5 & / \\
\hline $2017-61$ & 0.10 & 1.01 & 2.7 & $L R$ & 0.29 & 2.50 & 3.3 & $L R$ & 0.19 & 1.45 & 2.1 & $L R$ \\
\hline $2017-170$ & 0.083 & 2.76 & 2.2 & $L R$ & 0.23 & 6.06 & 2.6 & $L R$ & 0.083 & 15.33 & 0.9 & / \\
\hline 2017-176 & 0.12 & 5.20 & 3.2 & $L R$ & 0.53 & 12.28 & 6.0 & $L R$ & 0.15 & 12.42 & 1.7 & LR \\
\hline 2017-179 & 0.11 & 6.45 & 3.0 & LR & 0.18 & 74.42 & 2.0 & $L R$ & 0.20 & 25.54 & 2.2 & $L R$ \\
\hline
\end{tabular}

growth of several resistant isolates was even faster than that of 2017-48 (Table 4). Two resistant isolates, 201761 and 2017-170, exhibited increased spore production in potato sucrose broth (PSB) in comparison to the propiconazole-sensitive isolate $2017-11$. In addition, the virulence of the field-resistant isolate 2017-61 was stronger than that of the sensitive isolates $2017-11$ and 2017-48 (Table 4).

\section{Sequence and expression analysis of the CYP51 and its} encoded protein in propiconazole-resistant $U$. virens isolates A multisequence alignment showed no mutations in the coding region of CYP51, a reported target gene of DMIs, for all six propiconazole-resistant isolates (data not shown). However, an insertion of two bases (CC) was found 154-bp upstream of the CYP51 coding region in 2017-61, 2017-170 and 2017-179 (Fig. 2a). The GenBank accession numbers were MT701730, MT701731, and MT701732 for 2017-61, 2017-170, and 2017-179, respectively. The expression levels of CYP51 and its encoded protein were significantly increased in these three resistant isolates compared to the sensitive isolate 2017-11 (Fig. 2b, c). In addition, the expression of CYP51 was significantly up-regulated by propiconazole in all isolates. However, the protein accumulation of CYP51 was increased in sensitive isolate and also in resistant isolates without the ' $\mathrm{CC}$ ' mutation treated with $1 \mu \mathrm{g} / \mathrm{mL}$ of propiconazole, but not in propiconazoleresistant isolates with the "CC" mutation (Fig. 2c).

\section{Prediction of functional binding sites in the promoter of CYP51}

The promoter region predication of CYP51 in $U$. virens was made using the online BDGP database. In the promoter region, 118 and 132 putative transcription factor binding sites were predicted in sequence $\mathrm{A}$ (without the ' $\mathrm{CC}$ ' insertion mutation) and $\mathrm{B}$ (with the ' $\mathrm{CC}$ ' insertion mutation) using JASPAR online software, respectively (Additional file 1: Tables S1 and S2). There were 20 different putative binding sites between sequences $\mathrm{A}$ and $\mathrm{B}$. Among them, 16 binding sites were specific to sequence $\mathrm{B}$ with ' $\mathrm{CC}$ ' insertion mutations, and the binding abilities of two sites of sequence $B$ were greater than that of sequence A (Table 5).

\section{Discussion}

DMI fungicides such as Armure (30\% difenoconazolepropiconazole) and Horizon (tebuconazole) have been

Table 4 Mycelial growth, sporulation and virulence of propiconazole-resistant isolates

\begin{tabular}{|c|c|c|c|}
\hline \multirow[t]{2}{*}{ Isolates } & Mycelial growth & Spore production & Virulence \\
\hline & Colony diameter (cm) & Conidium in vitro $\left(\times 10^{5} / \mathrm{mL}\right)$ & Number of false smut balls per rice panicle \\
\hline $2017-11$ & $45.8 \pm 0.8 \mathrm{e}$ & 9.6 & 2.0 \\
\hline $2017-48$ & $42.6 \pm 0.8 b$ & 11.8 & 2.9 \\
\hline $2017-2$ & $43.4 \pm 0.6 \mathrm{bc}$ & 6.3 & 0.1 \\
\hline $2017-6$ & $37.5 \pm 0.7 a$ & 7.4 & 0.3 \\
\hline $2017-61$ & $41.0 \pm 0.8 b$ & 15.3 & 8.7 \\
\hline $2017-170$ & $42.0 \pm 0.4 b$ & 10.9 & 1.4 \\
\hline $2017-176$ & $45.0 \pm 1.7 \mathrm{~d}$ & 1.8 & 0 \\
\hline 2017-179 & $42.2 \pm 0.6 b$ & 2.9 & 0.8 \\
\hline
\end{tabular}

Values followed by different letters are significantly different at $P<0.05$ 


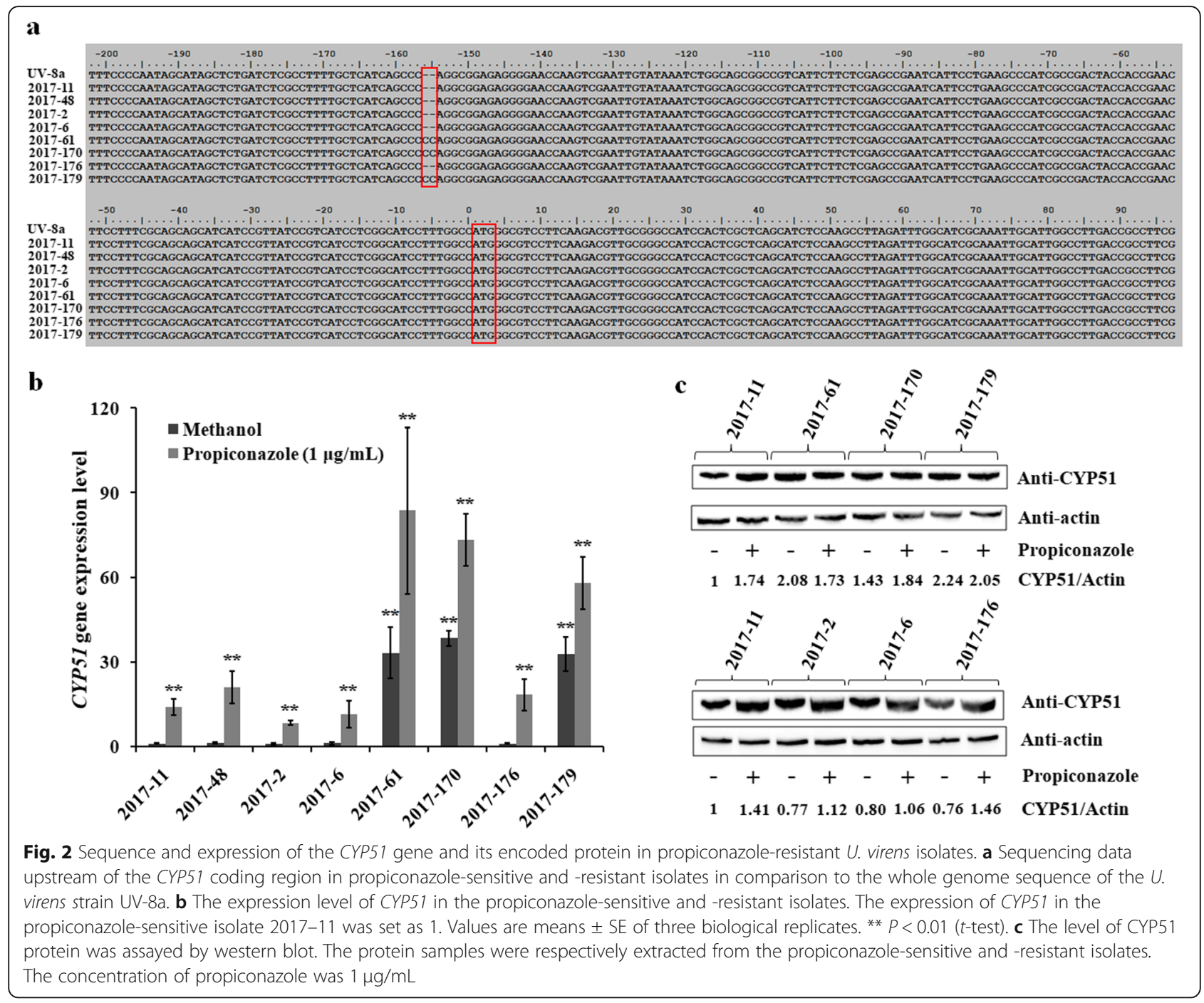

widely used for controlling RFS in the past two decades in China. Wang et al. (2015) obtained DMI-resistant mutants of $U$. virens by UV-irradiation in the laboratory. However, two propiconazole-resistant $U$. virens isolates were detected in Huai'an, Jiangsu Province, in 2015 (Zhou et al. 2019). In the current study, six out of $180 U$. virens isolates were found to be resistant to propiconazole. In addition to Huai'an, resistant isolates were also detected in Xuzhou and Jintan in 2017. The frequency of resistant isolates in Huai'an, Xuzhou, and Jintan were 3.0, 6.7 and $10.3 \%$, respectively (Table 1 ). These results indicated that the resistance of $U$. virens to DMIs evidently increased from 2015 to 2017.

After isolating the six propiconazole-resistant isolates, we determined their resistance levels and investigated the influence of DMI fungicide resistance on their fitness. We found that the sensitive isolates couldn't grow on PSA plate with $0.4 \mu \mathrm{g} / \mathrm{mL}$ of propiconazole, but the resistant isolates could grow on PSA plate containing $10 \mu \mathrm{g} / \mathrm{mL}$ of propiconazole (Fig. 1). The RF values (Table 2) of these resistant isolates further demonstrated that the propiconazole-resistance levels of $U$. virens were low. In addition, the propiconazoleresistant isolates 2017-61 and 2017-170 did not reduce in mycelia growth, sporulation and pathogenicity compared to those of propiconazole-sensitive isolates, which indicated that their fitness values were high (Table 4). The high fitness of propiconazole-resistant isolates suggested that the resistance of $U$. virens to DMI fungicides may continue to develop because of the strong competitiveness of resistant populations. Moreover, there was positive cross-resistance between propiconazole and other DMI fungicides (Table 3), indicating that the resistant isolates collected in the field were not selectively resistant to DMI fungicides at present.

As noted above, some pathogens are resistant to DMI fungicides. In most cases, resistance is linked to point 
Table 5 Differential functional binding sites predicted in the non-coding region upstream of CYP51 in U. virens with 'CC' insertion mutations (sequence B) relative to that without ' $C C^{\prime}$ insertion (sequence A) using the JASPAR database

\begin{tabular}{|c|c|c|c|c|c|c|}
\hline \multirow[t]{2}{*}{ Model ID } & \multirow{2}{*}{$\begin{array}{l}\text { Model } \\
\text { name }\end{array}$} & \multicolumn{2}{|l|}{ Score } & \multirow{2}{*}{$\begin{array}{l}\text { Predicted } \\
\text { proteins in } \\
U . \text { virens }\end{array}$} & \multirow{2}{*}{$\begin{array}{l}\text { Percent } \\
\text { identity (\%) }\end{array}$} & \multirow[t]{2}{*}{ Annotation } \\
\hline & & Sequence $\mathrm{A}$ & Sequence B & & & \\
\hline MA0351.1 & DOT6 & 9.81 & 10.63 & KDB15421.1 & 45.71 & MYB DNA-binding domain-containing protein \\
\hline MA0350.1 & TOD6 & 10.32 & 8.76 & KDB15421.1 & 51.43 & MYB DNA-binding domain-containing protein \\
\hline MA0316.1 & HAP5 & 5.51 & 9.05 & KDB16258.1 & 79.71 & CCAAT-binding protein subunit HAP5 \\
\hline MA0285.1 & CRZ1 & / & 8.99 & KDB16057.1 & 64.10 & $\mathrm{C} 2 \mathrm{H} 2$ type zinc finger domain-containing protein \\
\hline MA0313.1 & HAP2 & 2.36 & / & KDB14896.1 & 69.86 & CCAAT-binding complex subunit HAP2 \\
\hline MA0394.1 & STP1 & / & 3.44 & / & / & / \\
\hline MA0268.1 & ADR1 & / & 5.25 & KDB12570.1 & 36.65 & DNA binding regulatory protein AmdX \\
\hline MA0268.1 & ADR1 & / & 6.89 & KDB12570.1 & 36.65 & DNA binding regulatory protein AmdX \\
\hline MA0337.1 & MIG1 & / & 9.07 & KDB11811.1 & 72.86 & Carbon response regulator \\
\hline MA0341.1 & MSN2 & / & 7.93 & KDB13421.1 & 58.33 & Cutinase G-box binding protein \\
\hline MA0342.1 & MSN4 & / & 7.02 & KDB13421.1 & 54.67 & Cutinase G-box binding protein \\
\hline MA0362.1 & RDS2 & / & 5.91 & KDB19075.1 & 32.41 & Putative Zn cluster transcription factor Rds2 \\
\hline MA0276.1 & ASH1 & / & 4.71 & / & / & / \\
\hline MA0332.1 & MET28 & / & 5.71 & KDB18401.1 & 36.51 & Regulatory protein cys-3 \\
\hline MA0338.1 & MIG2 & / & 7.14 & / & / & / \\
\hline MA0339.1 & MIG3 & / & 7.53 & KDB11811.1 & 61.29 & Carbon response regulator \\
\hline MA0341.1 & MSN2 & / & 4.15 & KDB13421.1 & 58.33 & Cutinase G-box binding protein \\
\hline MA0342.1 & MSN4 & / & 4.13 & KDB13421.1 & 54.67 & Cutinase G-box binding protein \\
\hline MA0364.1 & REl1 & / & 5.71 & KDB10897.1 & 33.55 & $\mathrm{C} 2 \mathrm{H} 2$ type zinc finger containing protein \\
\hline MA0436.1 & YPR022C & / & 5.83 & KDB11753.1 & 44.07 & Zinc finger protein odd-paired-like \\
\hline
\end{tabular}

mutations in the target gene CYP51 (De Waard 1996; Marichal et al. 1999; Wyand and Brown 2005; Cools and Fraaije 2013). The Y137H mutation in CYP51 protein in the resistant mutant of $U$. virens, previously reported to be generated by UV irradiation, conferred resistance to tebuconazole. In addition, overexpression of CYP51 was observed in the tebuconazole-resistant mutant (Wang et al. 2015). However, in the current study, no mutations in the CYP51 gene were detected in any of the six propiconazole-resistant isolates, which was consistent with the resistant isolates of $U$. virens screened in 2015 (Zhou et al. 2019).

In M. fructicola, a 65 -bp sequence inserted at $113 \mathrm{bp}$ upstream of the MfCYP51 gene was reported to be associated with DMI fungicide resistance (Chen et al. 2017). In this study, the 'CC' insertion was found in three resistant isolates (2017-61, 2017-170, and 2017-179) at $154 \mathrm{bp}$ upstream of the CYP51 gene as previously reported in resistant isolate 88 collected in 2015 (Zhou et al. 2019). In addition, the expression levels of CYP51 and its encoded protein were significantly increased in these isolates (Fig. 2). The results suggested that ' $\mathrm{CC}$ ' insertion mutation may influence the expression of CYP51 by altering the ability of transcription factors to participate in regulation, which may reduce sensitivity of $U$. virens to DMI fungicides. In support of this inference, we used JASPAR (the largest transcription-factor binding profile database) to predict the functional binding sites of sequences with or without 'CC' insertion mutation (Wasserman and Sandelin 2004; Mathelier et al. 2014). As expected, 16 additional functional binding sites were found to be specific to the sequence with the ' $\mathrm{CC}$ ' insertion mutation rather than to that without the ' $\mathrm{CC}$ ' insertion mutation, and the binding abilities of two sites of sequence $B$ were stronger than that of sequence A (Table 5).

In addition, most of the predicted transcription factors were involved in cell wall integrity or osmotic stress. For example, the Myb-like HTH transcription factor Dot6 in Candida albicans was reported to be involved in the TOR signaling pathway (Chaillot et al. 2019), which was regulated in the responses to cell wall damaging stress in F. graminearum (Gu et al. 2015). Hap2/5, CRZ1, ADR1, MIG1/2/3, MSN2/4, and RDS2 have been reported to function directly in cell wall integrity or osmotic stress (Proft and Serrano 1999; Mendizabal et al. 2001; Wong et al. 2003; Panadero et al. 2007; Moreno et al. 2008; Nino-Vega et al. 2009; Li et al. 2013; Liu et al. 2013; Thewes 2014; Manzanares-Estreder et al. 2017; Jung et al. 2018; Miller et al. 2019). Combined with previous 
studies showing that the CYP51 gene encodes an enzyme that is part of the cell membrane, the current predictions further suggested that the resistance of $U$. virens to DMI fungicides may be related to CYP51 overexpression mediated by ' $\mathrm{CC}$ ' insertion mutations.

In our previous study, propiconazole stimulated the expression of CYP51 in both propiconazole-sensitive and -resistant isolates (Zhou et al. 2019). The same results were observed in this study (Fig. 2b). However, the level of CYP51-encoded protein was increased in propiconazolesensitive isolates and in propiconazole-resistant isolates that had no mutation with propiconazole treatment, whereas was unchanged in propiconazole-resistant isolates with the 'CC' insertion mutation (Fig. 2c). This result suggested that the DMI resistance may be induced by fungicides in the propiconazole-resistant isolates without any mutations. The underlying resistance mechanisms, for example, whether the $\mathrm{ABC}$ transporter is involved in these isolates, need to be further explored.

\section{Conclusions}

In this study, we showed a potential risk of $U$. virens resistance to DMI fungicides. Propiconazole-resistant isolates were found in three cities in Jiangsu Province. And all of them were positively cross-resistant to epoxiconazole, difenoconazole, and tebuconazole. In addition, two of them had high fitness. We suggest that it should be necessary to persistently monitor the resistance of $U$. virens to DMIs. DMIs should be valuable when used in alternation with other fungicides for the control of RFS in rice fields.

\section{Methods}

\section{Isolates of $U$. virens and fungicides}

$U$. virens isolates 2017-11, 2017-48, 2017-2, 2017-6, 2017-61, 2017-170, 2017-176, and 2017-179 were isolated from eight rice fields in Jiangsu Province of China in 2017 by single spore separation. All the isolates were stored in the rice diseases laboratory, Jiangsu Academy of Agricultural Science, China. Technical-grade propiconazole (96.3\%), epoxiconazole (96\%), difenoconazole (96\%), and tebuconazole (97.3\%) were provided by Jiangsu Fengdeng Pesticide Co., Ltd., Jiangsu Feixiang Chemical Co., Ltd., ZIBO DEZUN Chemical Co., and Beijing HWRK Chem Co., Ltd., respectively. All the fungicides were dissolved in methanol at $10 \mathrm{mg} / \mathrm{mL}$ and stored at $4{ }^{\circ} \mathrm{C}$ in the dark before further use.

\section{In vitro screening of propiconazole-resistant isolates}

In order to obtain propiconazole-resistant isolates, mycelia plugs ( $5 \mathrm{~mm}$ in diameter) of 14-day-old isolates were transferred to PSA (potato sucrose agar: $200 \mathrm{~g} / \mathrm{L}$ of potato, $20 \mathrm{~g} / \mathrm{L}$ of sucrose, and $15 \mathrm{~g} / \mathrm{L}$ of agar) plates containing $0.5 \mu \mathrm{g} / \mathrm{mL}$ propiconazole and then transferred to
PSA plates with $1 \mu \mathrm{g} / \mathrm{mL}$ propiconazole and incubated at $28^{\circ} \mathrm{C}$ for 14 days. The isolates that grew on the PSA plates containing $1 \mu \mathrm{g} / \mathrm{mL}$ propiconazole were propiconazoleresistant isolates. $\mathrm{EC}_{50}$ and $\mathrm{EC}_{90}$ represented the concentration of propiconazole that resulted in 50 and $90 \%$ inhibition of $U$. virens. The average $\mathrm{EC}_{50}$ value for the sensitive isolates was $0.05 \mu \mathrm{g} / \mathrm{mL}$ as Zhou et al. (2017) reported. The resistance factor (RF) in this study was the ratio of $\mathrm{EC}_{50}$ value of resistant isolates to average $\mathrm{EC}_{50}$ value $(0.05 \mu \mathrm{g} /$ $\mathrm{mL})$. RF values less than 10 , between 10 and 100 , and more than 100 were classified as low-resistance (LR), moderate-resistance (MR), and high-resistance (HR) strains, respectively.

\section{Cross-resistance analysis}

Cross resistance between propiconazole and other DMIs (epoxiconazole, difenoconazole, and tebuconazole) in $U$. virens was tested as previously described (Zhou et al. 2019). Mycelia plugs (5 $\mathrm{mm}$ in diameter) of each tested isolate were transferred to PSA plates containing different concentration of fungicides at $28^{\circ} \mathrm{C}$ for 16 days. For the propiconazole-sensitive isolates, the concentrations of propiconazole, epoxiconazole, difenoconazole, and tebuconazole were $0,0.0125,0.025,0.05,0.1,0.2$, and $0.4 \mu \mathrm{g} / \mathrm{mL}$. For the propiconazole-resistant isolates, the concentrations of these fungicides were $0,0.0195$, $0.078,0.3125,1.25,5$, and $10 \mu \mathrm{g} / \mathrm{mL}$. The 50 and $90 \%$ effective concentrations $\left(\mathrm{EC}_{50}\right.$ and $\mathrm{EC}_{90}$, respectively) of $U$. virens were calculated as described previously (Duan et al. 2018). There were three replicates of each concentration for each isolate. The experiment was repeated twice.

\section{Mycelial growth, sporulation and pathogenicity}

In order to test mycelial growth, mycelia plugs $(5 \mathrm{~mm}$ in diameter) of 14-day-old isolates were transferred to PSA plates, and then the diameter of the colony was measured after incubation at $28{ }^{\circ} \mathrm{C}$ for 18 days. In order to test sporulation, all tested isolates were cultured on PSA plates at $28^{\circ} \mathrm{C}$ for 14 days. Then two $5 \mathrm{~mm}$-diameter mycelia plugs were transferred into $100 \mathrm{~mL}$ of PSB, and the conidium was counted with a hemocytometer after shaking at $28^{\circ} \mathrm{C}, 150 \mathrm{rpm}$ for 7 days. In order to test virulence, the conidium and hyphal suspension was injected into rice panicles of Liangyoupeijiu as described by Yu et al. (2015). Each isolate was repeated three times and each experiment was conducted twice.

\section{Sequence analysis of the CYP51 gene}

Genomic DNA was extracted from the mycelia of all tested isolates using a DNA extraction kit (PD biotech, China). The primer pair Uv-CYP51-F/R listed in Additional file 1: Table S3 was designed to amplify the sequence of the CYP51 gene and its upstream region. PCR 
Table 6 Nucleotide sequences used to predict functional binding sites in non-coding region upstream of CYP51 in Ustilaginoidea virens

\begin{tabular}{ll}
\hline Name & Nucleotide sequences \\
\hline sequence A & gatctcgcctttgctcatcagcccaggcggagaggggaaccaagtcgaattgtataaatctggcagcggccgtcattcttctcgagccgaat \\
sequence B & gatctcgccttttgctcatcagcccCCaggcggagaggggaaccaagtcgaattgtataaatctggcagcggccgtcattcttctcgagccgaat \\
\hline
\end{tabular}

The nucleotide sequence in bold font is the predicted promoter region, and the uppercase letters indicate the insertion mutation in propiconazole-resistant isolates

amplifications were performed as described previously (Zhou et al. 2019). The enzyme used in PCR reactions was Phanta Max Super-Fidelity DNA Polymerase (Vazyme, China). The PCR products were purified using Fastpure gel DNA extraction mini kit (Vazyme, China) and sequenced by Tsingke Biological Technology.

\section{RT-qPCR and western blot assays}

All the tested isolates were cultured in PSB liquid medium at $28^{\circ} \mathrm{C}$ for 4 days, and then treated with $1 \mu \mathrm{g} /$ $\mathrm{mL}$ of propiconazole for $24 \mathrm{~h}$. Mycelia was harvested and washed with sterile water for total RNA and protein extraction. Total RNA and RT-qPCR were performed as described previously (Zhou et al. 2019). Briefly, RNA from mycelia of each isolate was extracted using a Total RNA Rapid Extraction Kit (BioTeke Co., Beijing, China), and reverse transcribed into cDNA using HiScript II 1st Strand cDNA Synthesis Kit (+gDNA wiper) (Vazyme Co., Nanjing, China) according to the manufacturer's instructions. RT-PCR was performed using primers listed in Additional file 1: Table S3. $\alpha$-tubulin was used as a reference gene. Each isolate was repeated three times. For protein extraction, $50 \mathrm{mg}$ of liquid nitrogen grinded mycelia was re-suspended in $500 \mu \mathrm{L}$ of protein extraction buffer [50 mM Tris- $\mathrm{HCl}, \mathrm{pH} 7.5,100 \mathrm{mM} \mathrm{NaCl}, 5$ $\mathrm{mM}$ ethylene diamine tetraacetic acid (EDTA), 1\% Triton X-100, $2 \mathrm{mM}$ phenylmethylsulfonyl fluoride (PMSF)] supplemented with protease inhibitor cocktail (Beyotime, Shanghai, China). Each sample was loaded onto 12\% SDS-PAGE gels. Anti-CYP51A1/CYP51 antibody (Abcam, Cambridge, England) and anti-beta actin antibody (Zoonbio, Nanjing, China) were used at 1:1000 for immunoblot analyses. After inoculation with secondary antibody anti-rabbit IgG-HRP $(1: 20,000)$ or anti-mouse IgG-HRP $(1: 20,000)$, chemiluminescence was detected as described previously (Li et al. 2019). In brief, the blots were determined by using an ECL substrate kit (Thermo Scientific, USA) and Tanon 5200 automatic chemiluminescent image analysis system (Tanon, Shanghai, China). The areas analyzed by Image J software was used to protein quantification.

\section{Functional binding sites predicted using the JASPAR database}

The promoter of CYP51 was predicted using the online BDGP database (http://www.fruitfly.org/seq_tools/ promoter.html). Then, sequence A (a $93 \mathrm{bp}$ nucleotide sequence of CYP51 promoter) and sequence B (a 95 bp nucleotide sequence of CYP51 promoter with the 'CC' insertion mutation) were used to predict functional binding sites in the JASPAR database (http:// jaspar.cgb.ki.se) (Table 6). The relative profile score threshold was set to $80 \%$.

\section{Supplementary information}

Supplementary information accompanies this paper at https://doi.org/10. 1186/s42483-020-00062-x.

Additional file 1: Table S1. Prediction of functional binding sites without ' $C C$ ' insertion sequences in the predicted promoter region of CYP51 in U. virens using the JASPAR database. Table S2. Prediction of functional binding sites with 'CC' insertion sequences in the predicted promoter region of CYP51 in U. virens using the JASPAR database. Table S3. Primers used in this study.

\section{Abbreviations}

DMls: Sterol demethylation inhibitors; $\mathrm{EC}_{50}$ : The concentration of fungicides resulting in 50\% inhibition of mycelia growth; $\mathrm{EC}_{90}$ : The concentration of fungicides resulting in $90 \%$ inhibition of mycelia growth; PSA: Potato sucrose agar; RT-qPCR: Reverse transcription-quantitative PCR; RF: Resistance factors; RFS: Rice false smut

Acknowledgements

Not applicable.

Authors' contributions

$\mathrm{XP}$ and $\mathrm{HC}$ conducted the experiments. All authors analyzed the data. XP, $\mathrm{HC}$ and $\mathrm{YL}$ wrote and revised the manuscript. All authors read and approved the final manuscript.

\section{Funding}

This study was supported by the National Key Research and Development Program of China (2016YFD0300706) and the Natural Science Foundation of Jiangsu Province (BK20160588).

Availability of data and materials Not applicable.

Ethics approval and consent to participate Not applicable.

Consent for publication

Not applicable.

Competing interests

The authors declare that they have no competing interests.

Received: 29 February 2020 Accepted: 14 July 2020

Published online: 27 August 2020

References

Ammar GA, Tryono R, Doll K, Karlovsky P, Deising HB, Wirsel SGR. Identification of $A B C$ transporter genes of Fusarium graminearum with roles in azole tolerance and/or virulence. PLoS One. 2013;8:e79042. 
Chaillot J, Tebbji F, Mallick J, Sellam A. Integration of growth and cell size via the TOR pathway and the Dot6 transcription factor in Candida albicans. Genetics. 2019;211:637-50

Chen S, Yuan N, Schnabel G, Luo C. Function of the genetic element 'Mona' associated with fungicide resistance in Monilinia fructicola. Mol Plant Pathol. 2017;18:90-7.

Chen Y, Zhang Y, Yao J, Li YF, Yang X, Wang WX, Zhang AF, Gao TC. Frequency distribution of sensitivity of Ustilaginoidea virens to four EBI fungicides, prochloraz, difenoconazole, propiconazole and tebuconazole, and their efficacy in controlling rice false smut in Anhui Province of China. Phytoparasitica. 2013;41:277-84.

Cools HJ, Bayon C, Atkins S, Lucas JA, Fraaije BA. Overexpression of the sterol 14 alpha-demethylase gene (MgCYP51) in Mycosphaerella graminicola isolates confers a novel azole fungicide sensitivity phenotype. Pest Manag Sci. 2012 68:1034-40.

Cools HJ, Fraaije BA. Update on mechanisms of azole resistance in Mycosphaerella graminicola and implications for future control. Pest Manag Sci. 2013;69:150-5.

Cools HJ, Parker JE, Kelly DE, Lucas JA, Fraaije BA, Kelly SL. Heterologous expression of mutated eburicol 14 alpha-demethylase (CYP51) proteins of Mycosphaerella graminicola to assess effects on azole fungicide sensitivity and intrinsic protein function. Appl Environ Microbiol. 2010;76:2866-72.

De Waard MA. Molecular genetics of resistance in fungi to azole fungicides. In: Brown TM, editor. Molecular genetics and evolution of pesticide resistance. American Chemical Society Symposium Series 645. Washington DC: American Chemical Society; 1996. p. 62-71.

Delye C, Bousset L, Corio-Costet MF. PCR cloning and detection of point mutations in the eburicol 14a-demethylase (CYP51) gene from Erysiphe graminis f. sp. hordei, a "recalcitrant" fungus. Curr Genet. 1998;34:399403.

Duan YB, Li MX, Zhao HH, Lu F, Wang JX, Zhou MG. Molecular and biological characteristics of laboratory metconazole-resistant mutants in Fusarium graminearum. Pestic Biochem Physiol. 2018;152:55-61.

Gu Q, Zhang C, Yu F, Yin Y, Shim WB, Ma ZH. Protein kinase FgSch9 serves as a mediator of the target of rapamycin and high osmolarity glycerol pathways and regulates multiple stress responses and secondary metabolism in Fusarium graminearum. Environ Microbiol. 2015;17:2661-76.

Jung WH, Son YE, Oh SH, Fu C, Kim HS, Kwak JH, et al. Had1 is required for cell wall integrity and fungal virulence in Cryptococcus neoformans. G3: Genes Genomes Genet. 2018;8:643-52.

Kretschmer M, Leroch M, Mosbach A, Walker AS, Fillinger S, Mernke D, et al. Fungicide-driven evolution and molecular basis of multidrug resistance in field populations of the grey mould fungus Botrytis cinerea. PLoS Pathog. 2009:5:e1000696

Li J, Huang HN, Zhu M, Huang S, Zhang WH, Dinesh-Kumar SP, Tao XR. A plant immune receptor adopts a two-step recognition mechanism to enhance viral effector perception. Mol Plant. 2019;12:248-62.

Li L, Yu Y, Wei J, Huang G, Zhang D, Liu Y, et al. Homologous HAP5 subunit from Picea wilsonii improved tolerance to salt and decreased sensitivity to ABA in transformed Arabidopsis. Planta. 2013;238:345-56.

Liu Q, Ying SH, Li JG, Tian CG, Feng MG. Insight into the transcriptional regulation of Msn2 required for conidiation, multi-stress responses and virulence of two entomopathogenic fungi. Fungal Genet Biol. 2013;54:42-51.

Luo CX, Cox KD, Amiri A, Schnabel G. Occurrence and detection of the DMI resistance-associated genetic element 'Mona' in Monilinia fructicola. Plant Dis. 2008;92:1099-103.

Luo CX, Schnabel G. The cytochrome P450 lanosterol 14 alpha-demethylase gene is a demethylation inhibitor fungicide resistance determinant in Monilinia fructicola field isolates from Georgia. Appl Environ Microbiol. 2008;74:359-66.

Ma ZH, Proffer TJ, Jacobs JL, Sundin GW. Overexpression of the 14 alphademethylase target gene (CYP51) mediates fungicide resistance in Blumeriella jaapii. Appl Environ Microbiol. 2006;72:2581-5.

Manzanares-Estreder S, Espi-Bardisa J, Alarcon B, Pascual-Ahuir A, Proft M. Multilayered control of peroxisomal activity upon salt stress in Saccharomyces cerevisiae. Mol Microbiol. 2017;104:851-68.

Marichal P, Koymans L, Willemsens S, Bellens D, Verhasselt P, Luyten W, et al. Contribution of mutations in the cytochrome P450 14a-demethylase (Erg11p, Cyp51p) to azole resistance in Candida albicans. Microbiology. 1999;145:2701-13.

Mathelier A, Zhao X, Zhang AW, Parcy F, Worsley-Hunt R, Arenillas DJ, et al. JASPAR 2014: an extensively expanded and updated open-access database of transcription factor binding profiles. Nucleic Acids Res. 2014;42:D142-7.
Mellado E, Diaz-Guerra TM, Cuenca-Estrella M, Rodriguez Tudela JL. Identification of two different 14-asterol demethylaserelated genes (cyp51A and cyp51B) in Aspergillus fumigatus and other Aspergillus species. J Clin Microbiol. 2001;39:2431-8.

Mendizabal I, Pascual-Ahuir A, Serrano R, de Larrinoa IF. Promoter sequences regulated by the calcineurin-activated transcription factor $\mathrm{Crz} 1$ in the yeast ENA1 gene. Mol Gen Genomics. 2001;265:801-11.

Miller ZD, Peralta PN, Mitchell PH, Kelley SS, Chiang VL, Pearson L, et al. Anatomical, physical, and mechanical properties of transgenic loblolly pine (Pinus teada L.) modififd for increased density. Wood Fiber Sci. 2019;51:173-82.

Moreno I, Tutrone N, Sentandreu R, Valentin E. Saccharomyces cerevisiae Rds2 transcription factor involvement in cell wall composition and architecture. Int Microbiol. 2008;11:57-63.

Nino-Vega GA, Sorais F, San-Blas G. Transcription levels of CHS5 and CHS4 genes in Paracoccidioides brasiliensis mycelial phase, respond to alterations in external osmolarity, oxidative stress and glucose concentration. Mycol Res. 2009;113:1091-6.

Panadero J, Hernandez-Lopez MJ, Prieto JA, Randez-Gil F. Overexpression of the calcineurin target CRZ1 provides freeze tolerance and enhances the fermentative capacity of baker's yeast. Appl Environ Microbiol. 2007;73:4824-31.

Price CL, Parker JE, Warrilow AGS, Kelly DE, Kelly SL. Azole fungicidesunderstanding resistance mechanisms in agricultural fungal pathogens. Pest Manag Sci. 2015;71:1054-8.

Proft M, Serrano R. Repressors and upstream repressing sequences of the stressregulated ENA1 gene in Saccharomyces cerevisiae: bZIP protein Sko1p confers HOG-dependent osmotic regulation. Mol Cell Biol. 1999;19:537-46.

Qiu J, Meng S, Deng Y, Huang S, Kou Y. Ustilaginoidea virens: a fungus infects rice flower and threats world rice production. Rice Sci. 2019;26:199-206.

Schepers HTAM. Fitness of isolates of Sphaerotheca fuliginea resistant or sensitive to fungicides which inhibit ergosterol biosynthesis. Neth J Plant Pathol. 1985; 91:65-76.

Thewes S. Calcineurin-Crz1 signaling in lower eukaryotes. Eukaryot Cell. 2014;13: 694-705.

Tsao S, Weber S, Cameron C, Nehme D, Ahmadzadeh E, Raymond M. Positive regulation of the Candida albicans multidrug efflux pump Cdr1p function by phosphorylation of its N-terminal extension. J Antimicrob Chemother. 2016;7: 3125-34.

Wang F, Lin Y, Yin WX, Peng YL, Schnabel G, Huang JB, et al. The Y137H mutation of VVCYP51 gene confers the reduced sensitivity to tebuconazole in Villosiclava virens. Sci Rep. 2015;5:17575.

Wasserman WW, Sandelin A. Applied bioinformatics for the identification of regulatory elements. Nat Rev Genet. 2004;5:276-87.

Wong CM, Ching YP, Zhou Y, Kung HF, Jin DY. Transcriptional regulation of yeast peroxiredoxin gene TSA2 through Hap1p, Rox1p, and Hap2/3/5p. Free Radic Biol Med. 2003;34:585-97.

Wyand RA, Brown JK. Sequence variation in the CYP51 gene of Blumeria graminis associated with resistance to sterol demethylase inhibiting fungicides. Fungal Genet Biol. 2005;42:726-35.

Yan X, Ma WB, Li Y, Wang H, Que YW, Ma ZH, et al. A sterol 14 alphademethylase is required for conidiation, virulence and for mediating sensitivity to sterol demethylation inhibitors by the rice blast fungus Magnaporthe oryzae. Fungal Genet Biol. 2011:48:144-53.

Yin Y, Liu X, Li B, Ma Z. Characterization of sterol demethylation inhibitor-resistant isolates of Fusarium asiaticum and $F$ graminearum collected from wheat in China. Phytopathology. 2009:99:487-97.

Yu M, Yu J, Hu J, Huang L, Wang Y, Yin X, et al. Identification of pathogenicityrelated genes in the rice pathogen Ustilaginoidea virens through random insertional mutagenesis. Fungal Genet Biol. 2015;76:10-9.

Zhou Y, Li H, Yu J, Yu M, Qi Z, Song T, et al. First report of propiconazole resistance in field isolates of Ustilaginoidea virens on rice in Jiangsu Province of East China. Plant Dis. 2017;101:5.

Zhou Y, Yu J, Pan X, Yu M, Du Y, Qi Z, et al. Characterization of propiconazole fieldresistant isolates of Ustilaginoidea virens. Pestic Biochem Physiol. 2019;153:144-51.

Zhou YL, Pan YJ, Xie XW, Zhu LH, Xu JL, Wang S, Li ZK. Genetic diversity of rice false smut fungus, Ustilaginoidea virens and its pronounced differentiation of populations in North China. J Phytopathol. 2008;156:559-64. 